ERANK R. METTS

SECRETARY

MEMORANDUM TO:

SUBJECT:
COMMONWEALTH OF KENTUCKV

DEPARTMENT OF TRANSPORTATION

Dlvision of Research

533 South Limestone

Lexington, $\mathrm{KY} 40508$

March 13, 1980
JOHN Y. BROWN, Jr. GOVERNOR

H-3-24

\author{
G. F. Kemper \\ State Highway Engineer \\ Chairman, Research Committee
}

"Effect of Interrupted Flow on Traffic Noise", Research Report 542, KYP-72-24; HPR-PL-1(15), Part III-B

This study is one of several which have dealt with the prediction of traffic noise. The first study (Report No. 379) involved on evaluation of the prediction procedure outlined in NCHRP Report 117. This study resulted in the development of a correction nomograph which was incorporated in to Kentucky's noise prediction procedure. A recent study (Report No. 534) involved an evaluation of a new, traffic noise prediction procedure which was adopted for use in Kentucky beginning January 1, 1980. In another study (Report No. 417), we investigated the effect of pavement texture on traffic noise and recommended adjustment factors to be used for various pavement types. The objectives of this study were to investigate the effect of interrupted flow on traffic noise and to recommend an adjustment factor, if necessary. Interrupted flow occurs when traffic is stopped by a traffic control device such as a stop sign or traffic signal.

The data showed that no adjustment factor is necessary to account for interrupted flow of traffic. It was recommended that the current procedure used for interrupted-flow locations be continued. In this procedure, no adjustment factor is used, and the traffic speed used in the prediction is the free-flowing vehicle speed (speed limit).

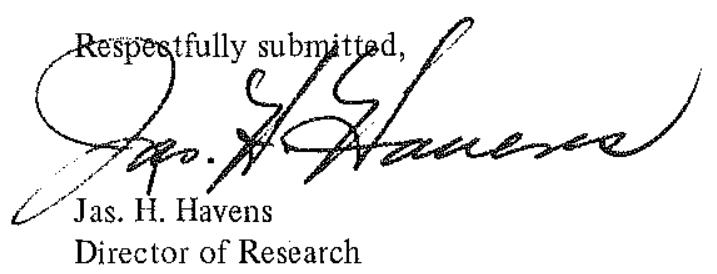

KRA/gh

cc: Research Committee 
Technical Report Documentation Page

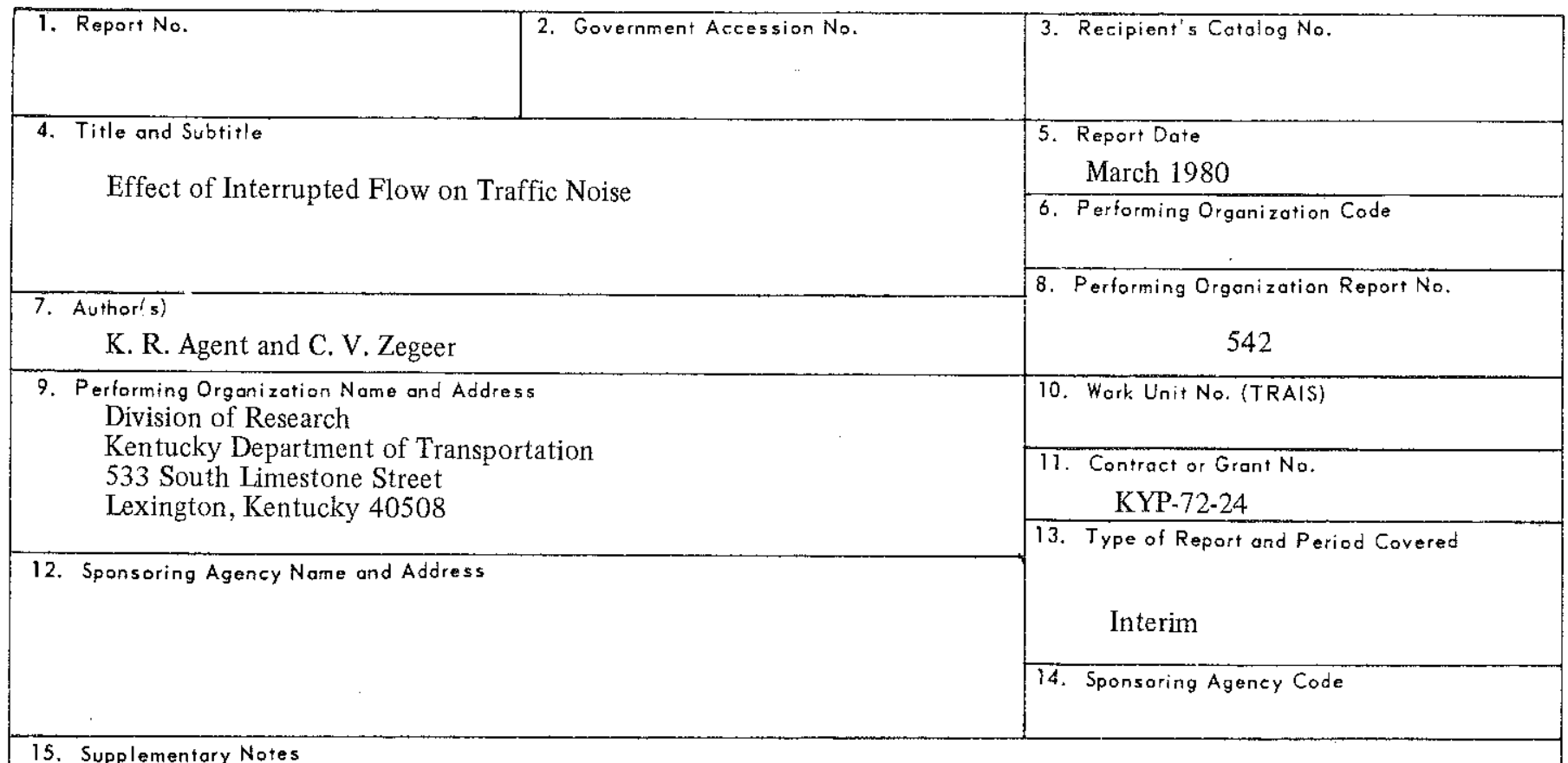

Study Title: Noise Abatement and Monitoring

16. Abstract

The objectives of this study were to investigate the effect interrupted traffic flow has on traffic noise and to determine an applicable adjustment factor. No attempt was made to develop a specific equation to predict noise levels at interrupted flow locations.

The basic method of analysis consisted of comparing the field data taken at intersections to determine if the measured noise levels changed as a function of distance from the intersection. Results showed that interrupted flow conditions did not cause an increase in the $\mathrm{L}_{10}$ or $\mathrm{L}_{\text {eq }}$ noise levels. Data taken before and after the installation of traffic signals showed that the addition of traffic signals did not significantly affect the average noise level. A comparison of measured and predicted noise levels showed general agreement.

It was concluded that no adjustment factor is necessary to account for interrupted flow. It was recommended that the current procedure used for interrupted flow locations be continued. In this procedure, no adjustment factor is used, and the traffic speed used in the prediction is the free-flowing vehicle speed (speed limit).

\begin{tabular}{|l|l|l|l|}
\hline 17. Key Words & 18. Distribution Statement \\
Traffic Noise \\
Interrupted Flow \\
Traffic Signal \\
Stop Sign
\end{tabular}


Research Report

542

\title{
EFFECT OF INTERRUPTED FLOW ON TRAFFIC NOISE
}

KYP-72-24; HPR-PL-1(15), Part III-B

by

Kenneth R. Agent

Research Engineer Principal

and

Charles V. Zegeer

Formerly Research Engineer Principal

\author{
Division of Research \\ Bureau of Highways \\ DEPARTMENT OF TRANSPORTATION
}

Commonweal th of Kentucky

\footnotetext{
The contents of this report reflect the views of the

authors who are responsible for the facts and the accuracy of the data presented herein.

The contents do not necessarily reflect the official views or policies of the Bureau of Highways.

The report does not represent a standard, specification,
} or regulation.

March 1980 


\section{INTRODUCTION}

Specific traffic noise levels for highway design were first given in Policy and Procedure Memorandum 90-2 of the Federal Highway Administration (1). To determine if noise levels of future highways would conform to these standards, it was necessary to predict noise levels. This presented many problems and has been the subject of several research studies resulting in methods to predict traffic noise level. The Kentucky Department of Transportation has been using the procedure outlined in NCHRP Report 117 (2). Past research investigated the accuracy of the prediction model. A correction nomograph was developed and incorporated into Kentucky's noise prediction procedure (3). Another study investigated the effect of pavement texture on traffic noise and recommended adjustment factors to be used for various pavement types (4). Another area which has been the source of confusion concerns the effect of interrupted flow on traffic noise. Interrupted flow occurs when traffic is interrupted by a traffic control device such as a stop sign or traffic signal. The original design guide contained an adjustment for interrupted flow (2); however, the adjustment was not considered accurate and was not usually used. The revised design guide outlined in NCHRP Report 174 did not contain any adjustment for interrupted flow (5). A traffic noise prediction computer program based on this procedure has been adopted by the Kentucky Department of Transportation to replace the NCHRP 117 procedure. The objectives of this study were to investigate the effect of interrupted flow on noise and to recommend an adjustment factor. No attempt was made to develop a specific equation to predict noise levels at interrupted flow locations.

\section{BACKGROUND}

In the past, two prediction procedures have been used primarily in the United States. These procedures were referred to as the NCHRP Report 117 method (2) and Transportation Systems Center (TSC) Method (6). The two methods were accepted by the Federal Highway Administration for use on federal-aid highway projects (7). Recently, a revised design guide (RDG) has been developed which uses additional data to develop a traffic noise prediction procedure (5). The NCHRP Report 117 method did contain an adjustment for interrupted flow; no such adjustment was present in the other methods. The NCHRP Report 117 adjustment of $2 \mathrm{dBA}$ for cars and $4 \mathrm{dBA}$ for trucks was added to the $\mathrm{L}_{10}$ noise level for the length of roadway affected by the interrupted flow. The $\mathrm{L}_{10}$ noise level is the level exceeded 10 percent of the time and is the level used in noise standards. A traffic control signal was assumed to have an influence on the operating noise of a vehicle over a distance of 1,000 feet $(305 \mathrm{~m})$ centered at the center of the signal area. However, this interrupted flow adjustment was not considered to be valid and was not generally used. Therefore, no adjustment is used for interrupted flow in the prediction methods accepted by the Federal Highway Administration.

Other prediction procedures have considered an adjustment for interrupted flow. The Ontario Highway Noise Prediction Method recommends that $\mathrm{L}_{10}$ leveis, emitted by interrupted traffic flow containing at least 60 heavy trucks per hour, be increased by about 2 or 3 dBA (8). The U. S. Department of Housing and Urban Development (HUD) Noise Assessment Guidelines also considers stop-and-go traffic (9). The HUD guidelines state that, if there is a traffic signal or stop sign within 800 feet $(244 \mathrm{~m})$ of a site, the total number of trucks should be multiplied by a factor of 5 . This adjustment is approximately equivalent to adding 3 to $5 \mathrm{dBA}$ to the freely flowing traffic noise prediction (10).

Measurements taken in New York City indicated that no adjustment should be made for freely flowing traffic to describe stop-and-go noise (10). Although accelerating vehicles produce more noise than vehicles traveling at a uniform speed, only a fraction of the rehicles would be accclerating at a given moment. At an interrupted flow location such as a traffic signal, vehicles at any given time would either be idling, decelerating, continuing at a uniform speed, or accelerating.

A British study yielded an equation for predicting $\mathrm{L}_{10}$ levels on urban streets (11). This model was specifically for use on typical urban streets where intersections, traffic signals, and other features influence the traffic and results in interrupted flow characteristics. The equation was derived as an alternate to the current equations available for predicting $\mathrm{L}_{10}$ noise for roads where traffic is freely flowing.

\section{PROCEDURE}

The procedure consisted of taking simultaneous recordings at various distances from the intersection under study. Normally, three recordings were taken. Each recording was of 10 minutes duration. Volumes, classified by type of vehicle, were determined for the mainline highway during each period. All the data were taken at a 5 -foot $(1.5-\mathrm{m})$ measurement height. An attempt was made to choose sites with zero grade, with the observer level with the roadway, and with no shielding in order to reduce the number of variables 
which might interfere. Sites were chosen so that there would be a large range in total traffic volume, percent trucks, and travel speeds. The method of traffic control at the intersections was either a signal or stop sign. The intersection approaches had to be a sufficient distance from another interrupted flow condition so that the vehicles were in a free-flowing condition as they approached the intersection. The intersections chosen were not in downtown areas where the noise levels would be affected by reflections off adjacent buildings.

The recordings were made using a precision sound-level meter and a strip-chart recorder. From the 10-minute recordings, noise levels at intervals slightly greater than one second were determined in the laboratory utilizing a digital data reduction system. The output was punched onto computer cards; and by means of a computer program, the $\mathrm{L}_{10}$ and $\mathrm{L}_{\mathrm{eq}}$ (noise equivalent level) noise levels were determined.

The intersections studied are cited in Table 1. Data were taken at 15 intersections. The traffic control at 12 of the intersections was a traffic signal, and the remaining three were four-way-stop locations. The average volume (vehicles per hour) varied from 485 to 2,160 (average of 1,309 ). The average percentage trucks varied from 2.5 to 21.4 . The speed limit of the locations varied from $35 \mathrm{mph}(15.6 \mathrm{~m} / \mathrm{s})$ to $55 \mathrm{mph}$ $(24.6 \mathrm{~m} / \mathrm{s})$. A total of 169 data sets were taken .resulting in 478 10-minute recordings.

The distance from the roadway was held constant for all data taken at a particular intersection. A sketch of a typical data collection setup is shown in Figure 1. The distance from the intersection was measured from the centerline of the cross street. At ten of the intersections (1 through 10 in Table 1), data were taken at 50 feet $(15.2 \mathrm{~m}), 100$ feet $(30.5 \mathrm{~m})$, and at 100 -foot $(30.5 \mathrm{~m})$ intervals up to a maximum of 1,000 feet $(305 \mathrm{~m})$ from the intersections. The 1,000 foot $(305-\mathrm{m})$ distance was chosen as the maximum distance the signal location might affect traffic noise. However, data were collected later at three additional intersections (11 through 13 in Table 1) where the distance from the intersection was substantially increased. The maximum distance was 4,000 feet $(1,219$ $\mathrm{m})$ at two of the intersections and 2,500 feet $(762 \mathrm{~m})$ at the other.

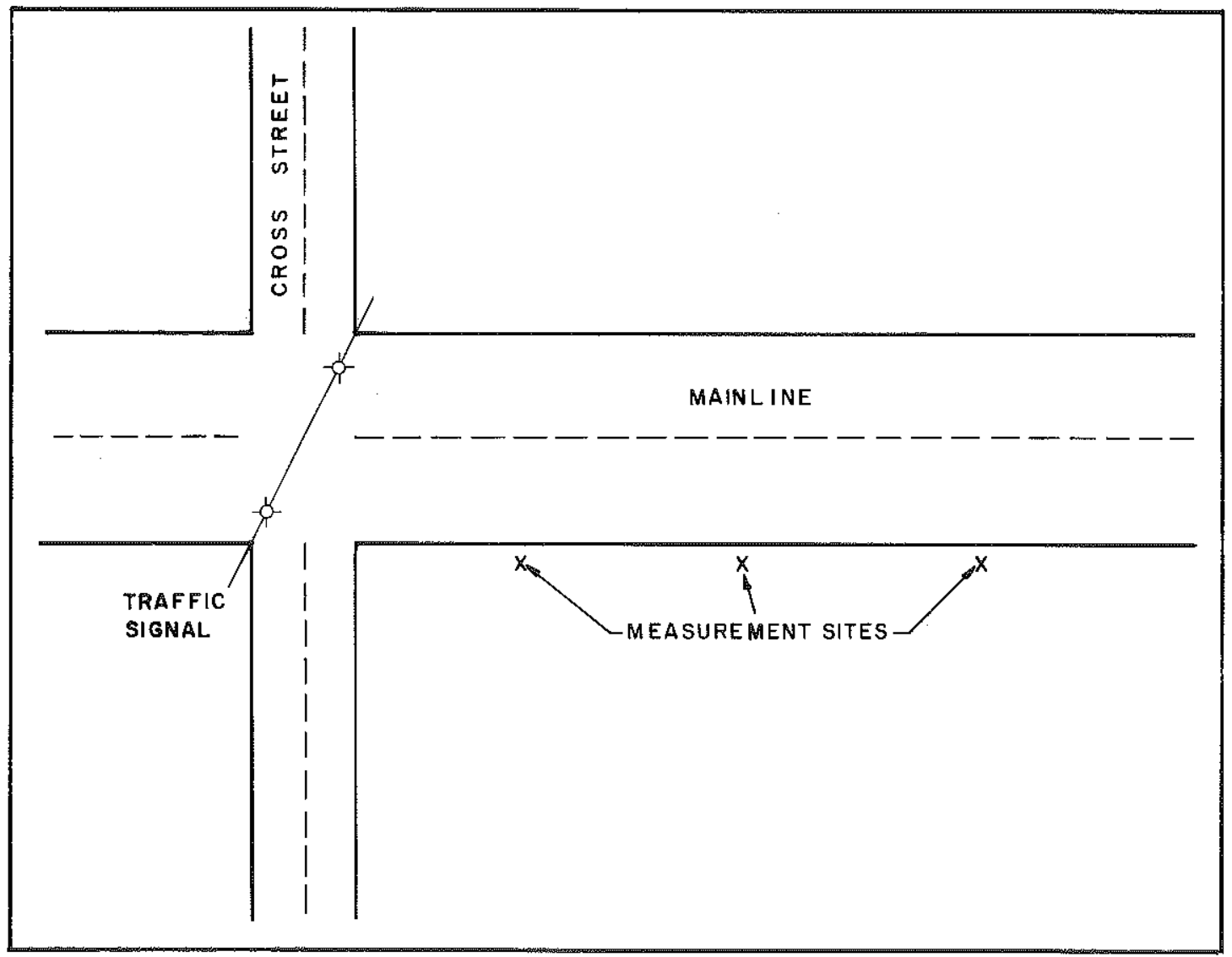

Figure 1. Typical Data Collection Setup. 
Average $L_{10}$ and $L_{e q}$ noise levels were calculated at the various distances from the intersection. The noise levels were then compared to determine if any changes occurred at the measurement sites as a function of distance from the intersection.

One additional type of data collection was done. Data were taken at two intersections (14 and 15 in Table 1) before and after installation of traffic signals. A comparison was then made to determine if the addition of the traffic signal changed the traffic noise levels around the intersection.

The measured $\mathrm{L}_{10}$ noise level at each intersection was also compared to the predicted $\mathrm{L}_{10}$ noise level. The predicted noise level was determined by three methods: (1) the procedure outlined in NCHRP Report 117 and employing the Kentucky correction nomograph, (2) the procedure outlined in the revised design guide (NCHRP Report 174) $\left(\mathrm{L}_{10}\right.$ nomograph), and (3) the FHWA level 1 Highway Traffic Noise Prediction Model (12).

\section{RESULTS}

The basic analysis consisted of comparing the field data taken at the intersections to determine if the measured noise levels changed as a function of distance from the intersection. At ten of the intersections, data were taken at 100 -foot $(30.5-\mathrm{m})$ intervals along the mainline up to a maximum distance of 1,000 feet (305 $\mathrm{m})$ from the interrupted flow location. The volumes remained fairly constant for all the data sets taken at any one site, and data were taken until a consistent average noise level was obtained at each distance. The results are shown in Tables 2 and 3.
While the noise levels at any one intersection varied several $\mathrm{dBA}$, no trends were found to indicate that the interrupted flow influenced the noise levels. This was true for both the $\mathrm{L}_{10}$ and $\mathrm{L}_{\mathrm{eq}}$ noise levels. The average noise level at each measurement distance for all 10 intersections was also determined and plotted (Figure 2). The range of noise levels at the various measurement distances was only $1.4 \mathrm{dBA}$ for the $\mathrm{L}_{10}$ noise levels and 1.2 dBA for the $\mathrm{L}_{\mathrm{eq}}$ noise levels.

Any influence that an interrupted flow condition had on noise levels should have been evident at the sites where data were taken up to 1,000 feet $(305 \mathrm{~m})$ from the cross street. However, as a further check, data were taken at three additional intersections. At these locations, data were taken at distances much farther from the cross street. The average noise level of the recordings taken 1,000 feet $(305 \mathrm{~m})$ or less from the cross street were compared to the average noise level at over 1,000 feet $(305 \mathrm{~m})$ (Table 4). The results of this comparison showed again that the interrupted flow did not cause an increase in the $\mathrm{L}_{10}$ or $\mathrm{L}_{\mathrm{eq}}$ noise levels. In fact, the average noise levels at distances over 1,000 feet $(305 \mathrm{~m})$ from the intersection were slightly higher. The increase in noise levels caused by the higher speeds at distances farther from the intersection more than offset the added acceleration and deceleration noise near the intersection.

The final data collection involved taking traffic noise data before and after installation of a traffic signal. The average $\mathrm{L}_{10}$ and $\mathrm{L}_{\mathrm{eq}}$ noise levels at the two test sites are given in Table 5. The results showed that the addition of traffic signals did not significantly affect the average noise level. 
TABLE 1. DESCRIPTION OF DATA COLLECTION LOCATIONS

\begin{tabular}{|c|c|c|c|c|c|c|c|c|c|c|c|c|c|}
\hline \multirow{2}{*}{$\begin{array}{l}\text { INTERSECTION } \\
\text { LOCATION }\end{array}$} & \multirow{2}{*}{$\begin{array}{l}\text { NTERSECTION } \\
\text { NUMBER }\end{array}$} & \multirow{2}{*}{$\begin{array}{l}\text { TYPE OF } \\
\text { TRAFFIC } \\
\text { CONTROL }\end{array}$} & \multicolumn{4}{|c|}{ AVERAGE VOLUME (VPH) ${ }^{\mathrm{a}}$} & \multirow{2}{*}{$\begin{array}{l}\text { AVERAGE } \\
\text { PERCENT } \\
\text { TRUCKS }\end{array}$} & \multicolumn{2}{|c|}{$\begin{array}{l}\text { SPEED } \\
\text { LIMIT }\end{array}$} & \multicolumn{2}{|c|}{$\begin{array}{c}\text { DISTANCE } \\
\text { FROM } \\
\text { MAINLINE }\end{array}$} & \multirow{2}{*}{$\begin{array}{c}\text { NUMBER } \\
\text { OF DATA } \\
\text { SETS }^{f}\end{array}$} & \multirow{2}{*}{$\begin{array}{l}\text { NUMBER OF } \\
\text { 10-MINUTE } \\
\text { RECORDINGS }\end{array}$} \\
\hline & & & AUTO & $M T^{b}$ & $\mathrm{HT}^{\mathrm{C}}$ & TOTAL & & $\mathrm{mph}$ & $\mathrm{m} / \mathrm{s}$ & feet & $\mathrm{m}$ & & \\
\hline Nicholasville-Jesselin & 1 & Signal & 1,722 & 36 & 12 & 1,770 & 2.7 & 40 & 17.9 & 45 & 13.7 & 10 & 26 \\
\hline Nicholasville-Arcadia Park & 2 & Signal & 2,106 & 42 & 12 & 2,160 & 2.5 & 40 & 17.9 & 40 & 12.2 & 10 & 26 \\
\hline Nicholasville-Rosemont & 3 & Signal & 1,927 & 48 & 11 & 1,986 & 3.0 & 40 & 17.9 & 40 & 12.2 & 9 & 25 \\
\hline Landsdowne-Malabu & 4 & Stop Sign & 444 & 12 & 0 & 456 & 2.6 & 35 & 15.6 & 47 & 14.3 & 8 & 23 \\
\hline New Circle-Woodhill & 5 & Signal & 1,776 & 90 & 42 & 1,903 & 6.9 & 45 & 20.1 & 78 & 23.8 & 14 & 42 \\
\hline Nicholasville-Zandale & 6 & Signal & 2,088 & 54 & 12 & 2,154 & 3.1 & 45 & 20.1 & 75 & 22.9 & 9 & 26 \\
\hline Harrodsburg-Pasadena & 7 & Signal & 748 & 36 & 14 & 998 & 5.0 & 55 & 24.6 & 78 & 23.8 & 12 & 36 \\
\hline Richmond-Chinoe & 8 & Signal & 1,074 & 42 & 6 & 1,122 & 4.3 & 35 & 15.6 & 65 & 19.8 & 12 & 24 \\
\hline New Circle-Bryan Station & 9 & Signal & 1,620 & 72 & 48 & 1,740 & 6.9 & 45 & 20.1 & 50 & 15.2 & 9 & 35 \\
\hline Lansdowne-Reynolds & 10 & Stop Sign & 468 & 12 & 5 & 485 & 3.5 & 35 & 15.6 & 50 & 15.2 & 9 & 27 \\
\hline Harrodsburg New Circle & 11 & Signal & 666 & 36 & 18 & 720 & 7.5 & 55 & 24.6 & & 0 & 13 & 37 \\
\hline Nicholasville-Wilson Downing & 12 & Signal & 1,062 & 42 & 78 & 1,182 & 10.2 & 45 & 20.1 & 52 & 15.8 & 16 & 43 \\
\hline Danville Bypass - KY 34 & 13 & Stop Sign & 444 & 18 & 24 & 486 & 8.6 & 55 & 24.6 & 21 & 6.4 & 14 & 41 \\
\hline Newtown - Nandino & 14 & Signal & 792 & 72 & 144 & 1,008 & 21.4 & 55 & 24.6 & 41 & 12.5 & 12 & 35 \\
\hline Tates Creek-Albany & 15 & Signal & 1,398 & 54 & 12 & 1,464 & 4.5 & 45 & 20.1 & 58 & 17.7 & 11 & 32 \\
\hline
\end{tabular}

${ }^{a}$ Volume on mainline, the street listed first.

${ }^{\mathrm{b}}$ Medium trucks (MT) generally refer to gasoline-powered, two-axle, six-wheeled vehicles.

${ }^{c_{H}}$ Heavy trucks (HT) refer generally to diesel-powered, three-or-more-axle truck combinations.

${ }^{d}$ The percent of medium plus heavy trucks in the traffic stream.

${ }^{\mathrm{e}}$ Distance from the centerline of the mainline highway.

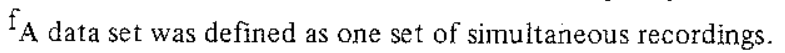


TABLE 2. AVERAGE $L_{10}$ NOISE LEVELS AT DISTANCES UP TO 1,000 FEET $(305 \mathrm{~m})$ FROM AN INTERRUPTED FLOW SITE

\begin{tabular}{|c|c|c|c|c|c|c|c|c|c|c|c|}
\hline \multirow{2}{*}{$\begin{array}{l}\text { INTERSECTION } \\
\text { NUMBER }\end{array}$} & \multicolumn{10}{|c|}{$\begin{array}{c}\text { AVERAGE } \mathrm{L}_{10} \text { NOISE LEVEL (dBA) } \\
\text { DISTANCE (FEET) (m) FROM INTERSECTION }\end{array}$} & \multirow[b]{2}{*}{$1,000(305)$} \\
\hline & $50(15.2)$ & $100(30.5)$ & $200(61.0)$ & $300(91.4)$ & $400(122)$ & $500(152)$ & $600(183)$ & $700(213)$ & $800(244)$ & $900(274)$ & \\
\hline 1 & 73.0 & 74.9 & 75.6 & 73.4 & 74.3 & 76.8 & 74.4 & 76.9 & 76.4 & 76.9 & 75.9 \\
\hline 2 & 77.6 & 77.4 & 77.2 & 76.9 & 77.1 & 77.1 & 75.2 & 77.1 & 76.5 & 77.2 & 76.4 \\
\hline 3 & 74.0 & 77.4 & 76.0 & 74.3 & 75.0 & 76.0 & 76.2 & 77.2 & 75.3 & 80.3 & 80.3 \\
\hline 4 & 65.0 & 63.6 & 65.6 & 70.2 & 70.3 & 65.8 & 68.9 & 70.9 & 71.8 & 69.0 & 71.6 \\
\hline 5 & 74.2 & 72.7 & 74.3 & 73.6 & 73.7 & 73.7 & 73.8 & 73.6 & 74.2 & 73.7 & 71.0 \\
\hline 6 & 70.1 & 71.1 & 67.6 & 69.3 & 66.8 & 71.0 & 72.3 & 70.5 & 72.3 & 70.8 & 70.3 \\
\hline 7 & 66.6 & 67.8 & 67.3 & 68.3 & 67.4 & 65.3 & 65.4 & 66.9 & 64.2 & 66.9 & 64.2 \\
\hline 8 & 72.3 & 70.9 & 70.0 & 69.8 & 69.4 & 70.7 & 71.9 & 72.6 & 72.1 & 71.8 & 70.4 \\
\hline 9 & 77.5 & 78.2 & 78.7 & 77.6 & 74.8 & 75.0 & 76.1 & 76.8 & 75.4 & 75.7 & 76.8 \\
\hline 10 & 66.6 & 65.8 & 66.2 & 66.2 & 66.6 & 63.8 & 66.1 & 66.8 & 64.1 & 62.6 & 65.6 \\
\hline Average & 71.7 & 72.0 & 71.9 & 72.0 & 71.5 & 71.5 & 72.0 & 72.9 & 72.2 & 72.5 & 72.3 \\
\hline
\end{tabular}

${ }^{\mathrm{a} D i s t a n c e}$ measured along the mainline from the centerline of the cross street. 
TABLE 3. AVERAGE $L_{\text {eg }}$ NOISE LEVELS AT DISTANCES UP TO 1,000 FEET $(305 \mathrm{~m})$ FROM AN INTERRUPTED FLOW SITE

\begin{tabular}{|c|c|c|c|c|c|c|c|c|c|c|c|}
\hline \multirow{2}{*}{$\begin{array}{l}\text { INTERSECTION } \\
\text { NUMBER }\end{array}$} & \multicolumn{10}{|c|}{$\begin{array}{l}\text { AVERAGE } \text { L }_{\text {eq }} \text { NOISE LEVEL (dBA) } \\
\text { DISTANCE }\left(\text { FEET) (m) FROM INTERSECTION }{ }^{a}\right.\end{array}$} & \multirow[b]{2}{*}{$1,000(305)$} \\
\hline & $50(15.2)$ & $100(30.5)$ & $200(61.0)$ & $300(91.4)$ & $400(122)$ & $500(152)$ & $600(183)$ & $700(213)$ & $800(244)$ & $900(274)$ & \\
\hline 1 & 70.2 & 72.0 & 72.7 & 71.1 & 71.1 & 73.1 & 70.8 & 72.5 & 72.3 & 74.0 & 72.9 \\
\hline 2 & 75.1 & 74.3 & 73.6 & 73.4 & 73.6 & 73.5 & 72.2 & 72.9 & 73.8 & 74.2 & 72.9 \\
\hline 3 & 70.5 & 74.4 & 76.6 & 72.3 & 71.6 & 72.7 & 72.9 & 73.0 & 72.4 & 78.5 & 76.9 \\
\hline 4 & 61.5 & 60.3 & 62.6 & 66.8 & 66.0 & 63.5 & 64.4 & 66.4 & 67.3 & 65.0 & 67.5 \\
\hline 5 & 71.2 & 69.3 & 70.9 & 69.9 & 69.8 & 69.9 & 69.9 & 69.6 & 70.8 & 70.2 & 67.7 \\
\hline 6 & 67.0 & 68.8 & 64.8 & 66.5 & 63.5 & 67.1 & 70.3 & 67.8 & 69.1 & 68.3 & 66.8 \\
\hline 7 & 63.3 & 65.2 & 63.5 & 65.7 & 64.0 & 62.3 & 61.6 & 65.1 & 61.1 & 63.8 & 60.8 \\
\hline 8 & 69.0 & 68.7 & 67.3 & 66.2 & 67.8 & 67.8 & 67.5 & 68.5 & 68.3 & 67.8 & 66.6 \\
\hline 9 & 75.1 & 75.7 & 74.7 & 73.9 & 71.3 & 71.7 & 72.8 & 73.5 & 72.3 & 72.8 & 73.4 \\
\hline 10 & 63.7 & 62.4 & 62.2 & 64.7 & 63.2 & 61.9 & 61.7 & 62.2 & 61.0 & 59.0 & 61.1 \\
\hline Average & 68.7 & 69.1 & 68.9 & 69.0 & 68.2 & 68.4 & 68.4 & 69.2 & 68.8 & 69.4 & 68.7 \\
\hline
\end{tabular}

${ }^{a}$ Distance measured along the mainline from the centerline of the cross street. 


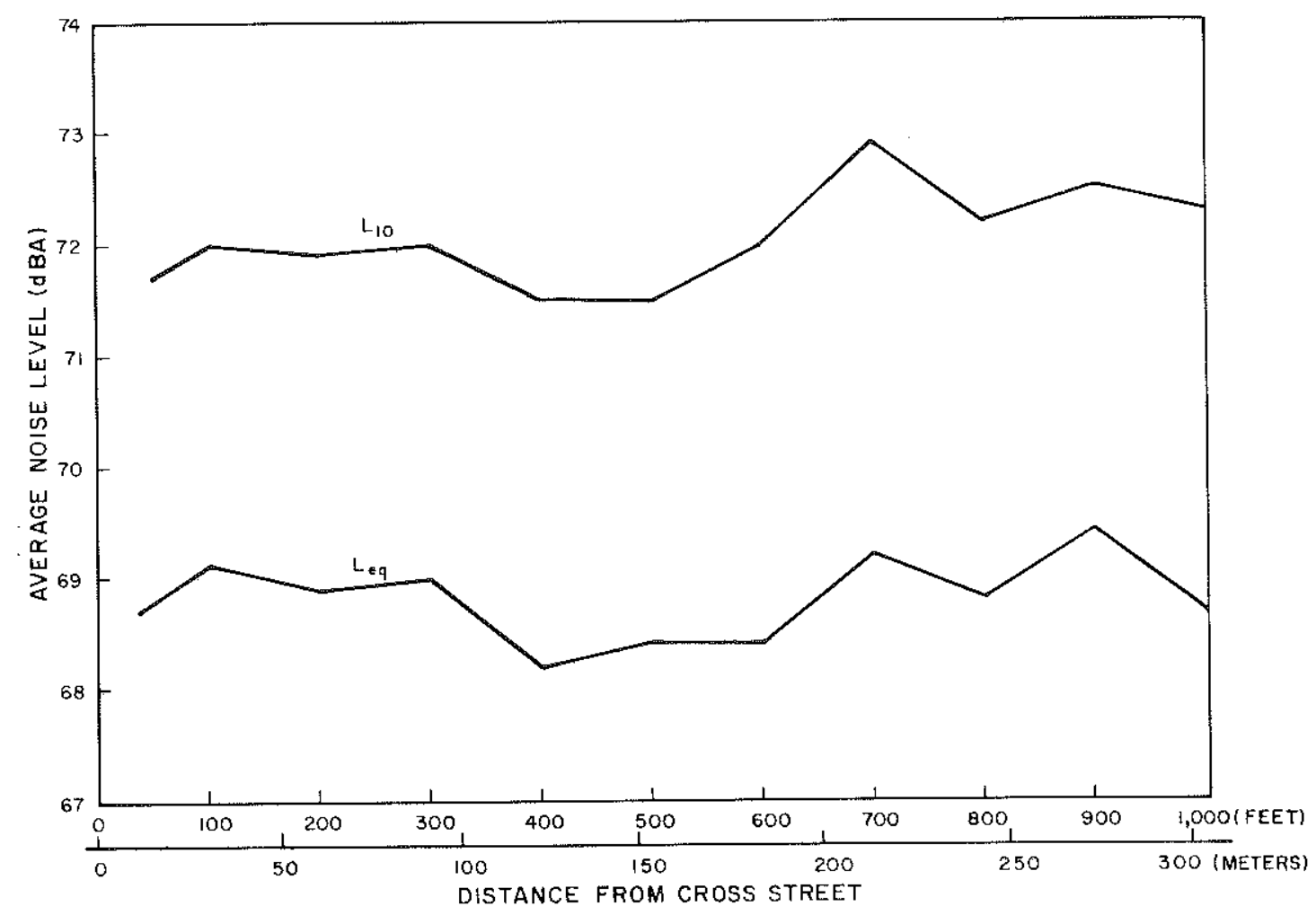

Figure 2. Variation in $L_{10}$ and $L_{e q}$ Noise Levels for Distances up to 1,000 feet (305 $\mathrm{m}$ ) from the Cross Street.

TABLE 4. AVERAGE NOISE LEVEL AT VARIOUS DISTANCES FROM INTERSECTIONS

AVERAGE NOISE LEVEL

\begin{tabular}{|c|c|c|c|c|}
\hline \multirow{2}{*}{$\begin{array}{l}\text { INTERSECTION } \\
\text { NUMBER }\end{array}$} & \multicolumn{2}{|c|}{$\begin{array}{c}\mathrm{L}_{10} \\
\text { DISTANCE FROM INTERSECTION }\end{array}$} & \multicolumn{2}{|c|}{$\stackrel{\mathrm{L}_{\mathrm{eg}}}{\text { DISTANCE FROM INTERSECTION }}$} \\
\hline & $\begin{array}{l}1,000 \text { FEET }(305 \mathrm{~m}) \\
\text { OR LESS }\end{array}$ & $\begin{array}{l}\text { OVER } 1,00 \text { FEET } \\
(305 \mathrm{~m})\end{array}$ & $\begin{array}{l}\text { 1,000 FEET }(305 \mathrm{~m}) \\
\text { OR LESS }\end{array}$ & $\begin{array}{l}\text { OVER } 1,00 \text { FEET } \\
(305 \mathrm{~m})\end{array}$ \\
\hline 11 & 74.7 & 74.3 & 70.2 & 70.4 \\
\hline 12 & 77.8 & 80.6 & 74.3 & 77.0 \\
\hline 13 & 73.2 & 75.7 & 70.5 & 71.9 \\
\hline Average & 75.2 & 76.9 & 71.7 & 73.1 \\
\hline
\end{tabular}


TABLE 5. CHANGE IN NOISE LEVEL AFTER INSTALLATION

OF A TRAFFIC SIGNAL

\begin{tabular}{ccccccc}
\hline & \multicolumn{2}{c}{$\begin{array}{c}\text { AVERAGE } L_{10} \\
\text { NOISE LEVEL }\end{array}$} & & \multicolumn{2}{c}{$\begin{array}{c}\text { AVERAGE } L_{\text {eq }} \\
\text { NOISE LEVEL }\end{array}$} \\
\cline { 2 - 3 } $\begin{array}{c}\text { INTERSECTION } \\
\text { NUMBER }\end{array}$ & BEFORE & AFTER & & BEFORE & AFTER \\
\hline $14^{\mathrm{a}}$ & 81.5 & 80.9 & & 76.5 & 77.8 \\
$15^{\mathrm{b}}$ & 76.5 & 77.3 & & 72.8 & 73.1 \\
\hline
\end{tabular}

${ }^{\mathrm{a}}$ Data were taken from 100 feet $(30.5 \mathrm{~m})$

to 2,500 feet $(762 \mathrm{~m}$ ) from the signal.

${ }^{\mathrm{b}}$ Data were taken from 50 feet $(15.2 \mathrm{~m})$

to 2,000 feet $(610 \mathrm{~m})$ from the signal.

Another analysis compared the measured and predicted noise levels (Table 6). The data given in Table 1 were used to predict a noise level at each site. The noise contributed by the cross street was not a factor in the predicted values. Three methods of prediction were used. First, the method outlined in NCHRP Report 117 (2) and modified by the correction nomograph developed for Kentucky (3) was used. This has been the procedure used in Kentucky for the past several years. As currently used in Kentucky, the speed limit was used as the traffic speed in the predictions. Second, the revised design guide method as outlined in NCHRP Report 174 (5) was used. The short method was used. This involved use of an $\mathrm{L}_{10}$ nomograph. The short method was designed to overpredict expected noise levels because the short method includes many assumptions and simplifications. The amount of overprediction would depend on the complexity of the real highway situations. However, since the study locations were selected so that no adjustments would be necessary, the amount of overprediction should be a minimum. The third method was the FHWA Level I Highway Traffic Noise Prediction Model (SNAP 1) 12). This is the recently adopted procedure used in Kentucky. A limitation of the computer program was that it does not predict noise for observer-to-roadway distances under 50 feet $(15 \mathrm{~m})$. Using this program, both $\mathrm{L}_{10}$ and $\mathrm{L}_{\mathrm{eq}}$ noise levels were predicted and compared to measured values. The average noise values for all the intersections showed that there was an overall good agreement between measured and predicted values. There was a tendency for the "NCHRP Report-117-plus-correction-factor" and the SNAP 1 procedures to underpredict the measured $\mathrm{L}_{10}$ values. There was only an overall average underprediction of 2 dBA using the revised NCHRP Report 117 procedure. The very short distances used and the generally low truck volumes probably accounted for some of the differences. In fact, these predictions were obtained by manual calculations because of inaccuracies in computer procedures for the very short distances. The predicted $\mathrm{L}_{10}$ values using the SNAP 1 program under predicted the measured values. However, the average of the $\mathrm{L}_{\mathrm{eq}}$ predicted values using this procedure was only $1 \mathrm{dBA}$ lower than the average of the measured $\mathrm{L}_{\mathrm{eq}}$ values.

\section{RECOMMENDATION}

The measured noise data showed that no adjustment factor is necessary to account for interrupted flow of traffic. It is recommended that the current procedure used in Kentucky for interrupted flow locations be continued. In this procedure, no adjustment factor is used, and the traffic speed used in the prediction is the free-flowing vehicle speed (speed limit). 


\section{TABLE 6. COMPARISON OF MEASURED AND PREDICTED NOISE LEVELS}

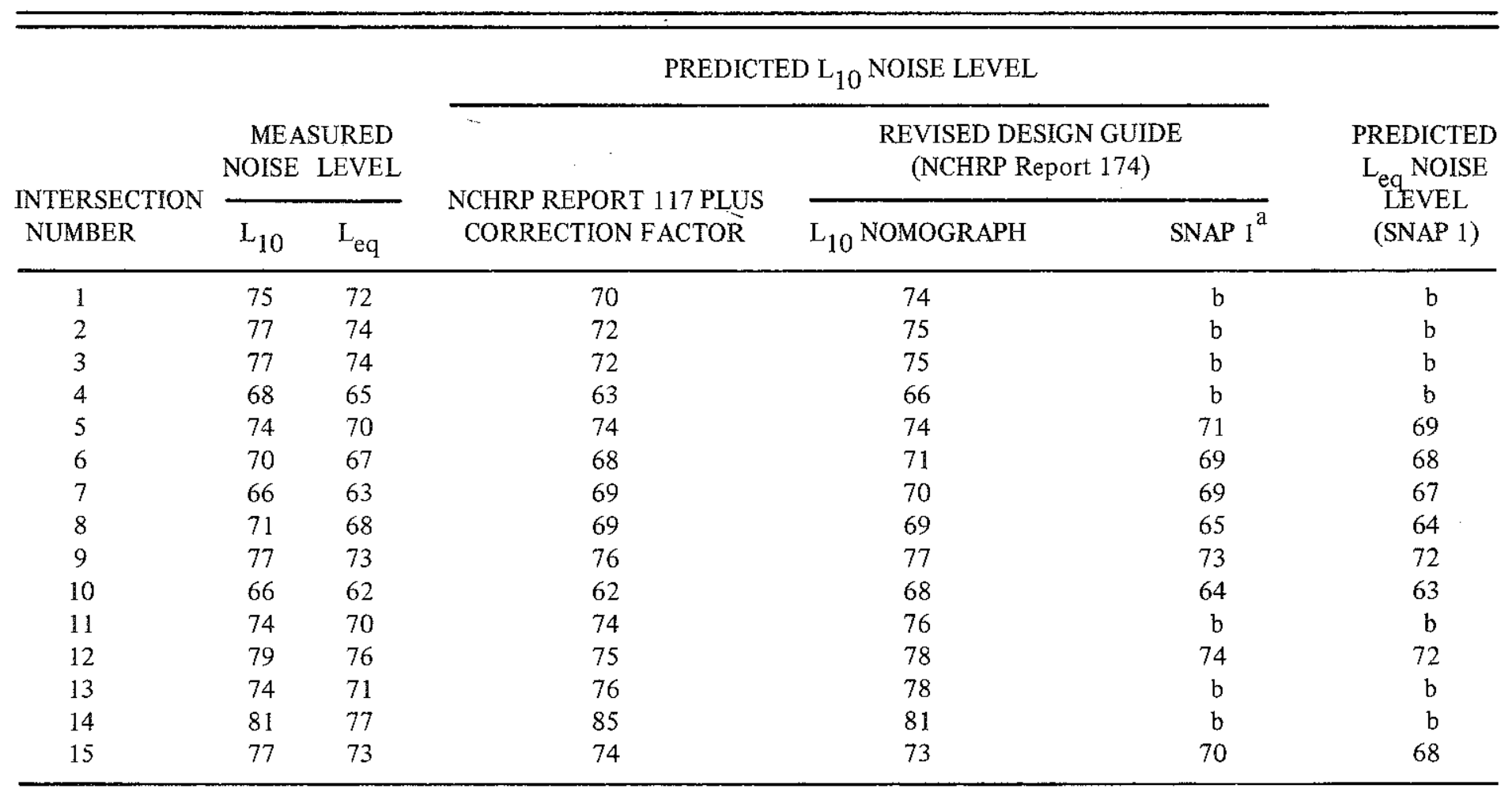

${ }^{a}$ Simplified Noise Analysis Program 1.0

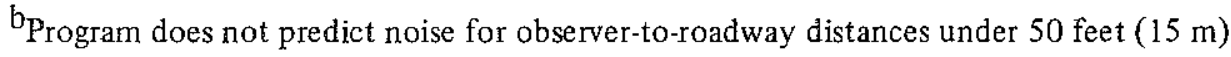




\section{REFERENCES}

1. Policy and Procedure Memorandum 90-2, Federal Highway Administration, April 26, 1972.

2. Gordon, C. G.; Galloway, W. J.; Kugler, B. A.; and Nelson, D. L.; Highway Noise - A Design Guide for Highway Engineers, National Cooperative Highway Research Program Report No. 117, Highway Research Board, 1971.

3. Agent, K. R.; and Zegeer, C. V.; Evaluation of the Traffic Noise Prediction Procedure, Report 379, Division of Research, Department of Transportation, November 1973.

4. Agent, K. R.; and Zegeer, C. V.; Effect of Pavement Texture on Traffic Noise, Report 417, Division of Research, Kentucky Department of Transportation, February 1975.

5. Kugler, B. A.; Commins, D. E.; and Galloway, W. J., Highway Noise -- A Design Guide for Prediction and Control, National Cooperative Highway Research Program Report 174, Transportation, Research Board, 1976.

6. Kurse, V. J.; Levison, W. H.; and Serben, S.; User's Manual for the Prediction of Road Traffic Noise Computer Program, Transportation Systems Center, U. S. Department of Transportation, Report No. DOT-TSC-315-1, May 1972.
7. Highway Traffic Noise Prediction Methods, Research Circular 175, Transportation Research Board, January 1974.

8. Hajek, J. J.; Ontario Highway Noise Prediction Method, Research and Development Division, Ministry of Transportation and Communication, Ontario, January 1975.

9. Schultz, T. J.; and McMahon, N. M.; Noise Assessment Guidelines, U. S. Department of Housing and Urban Development, Washington, D. C., August 1971.

10. Fundamentals and Abatement of Highway Traffic Noise, U. S. Department of Transportation, Report No. FHWA-HHJ-HEV-73-7976-1, June 1973.

11. Gilbert, D.; Noise from Road Traffic (Interrupted Flow), Journal of Sound and Vibration, Vol 51, pp 171-181, 1977.

12. Rudder, F. F.; and Lam, D. F.; FHWA Highway Traffic Noise Prediction Model, Sciences Applications, Inc., January 1979. 